\title{
Genotypic and phenotypic diversity differences of presumptive commensal and avian pathogenic E. coli
}

Article

Accepted Version

Al-Kandari, F. and Woodward, M. J. (2019) Genotypic and phenotypic diversity differences of presumptive commensal and avian pathogenic E. coli. British Poultry Science, 60 (1). pp. 79-86. ISSN 1466-1799 doi:

https://doi.org/10.1080/00071668.2018.1544415 Available at https://centaur.reading.ac.uk/80619/

It is advisable to refer to the publisher's version if you intend to cite from the work. See Guidance on citing.

To link to this article DOI: http://dx.doi.org/10.1080/00071668.2018.1544415

Publisher: Taylor \& Francis

All outputs in CentAUR are protected by Intellectual Property Rights law, including copyright law. Copyright and IPR is retained by the creators or other copyright holders. Terms and conditions for use of this material are defined in the End User Agreement.

www.reading.ac.uk/centaur 
Central Archive at the University of Reading

Reading's research outputs online 
Publisher: Taylor \& Francis \& British Poultry Science Ltd

Journal: British Poultry Science

DOI: $10.1080 / 00071668.2018 .1544415$

Genotypic and phenotypic diversity differences of presumptive commensal and avian pathogenic $E$. coli

Fatemah Al-Kandari and Martin J. Woodward

Department of Food and Nutrition Science, School of Chemistry, University of Reading.

Address: The University of Reading, PO Box 226, Whiteknights, READING, RG6 6AP

Corresponding Author:

Fatemah Al-Kandari Phone: +9659442204

Email: dr.f.a.h.alkandari@gmail.com

Accepted for publication 5 October 2018 


\section{ABSTRACT}

1. The objective of the experiment was to characterise the genotypic and phenotypic differences between presumptive commensal E. coli and avian pathogenic E. coli (APEC) of poultry.

2. DNA was extracted from 65 confirmed APEC E. coli from chicken, 100 presumptive commensal E. coli from healthy turkey and 35 from healthy chicken. Enterobacterial repetitive intergenic consensus PCR (ERIC-PCR) and virulence factors genotyping was performed to characterise genetic features.

3. Carbon source utilisation and antimicrobial susceptibility tests were performed to characterise phenotypic features of isolates.

4. The genetic divergence between $E$. coli strains tested by ERIC-PCR profiles and virulence associated genes showed a clear genetic separation between E. coli APEC and turkey E. coli strains.

5. The carbon utilisation profile of turkey isolates was different from chicken and APEC strains; whereas antimicrobial susceptibility was highest for turkey isolates (53\%), and lowest for APEC strains $(33.8 \%)$.

6. The study showed a significant negative correlation between utilisation of arabitol and adonitol with different virulence determinants tested, which suggests that the ability to utilise some uncommon carbon sources may be used to discriminate between presumptive commensal E. coli and APEC.

Keywords: APEC; E. coli; commensal; virulence genes; antimicrobial resistance; carbon source. 


\section{Introduction}

Escherichia coli is one of the most frequent causal agents of common bacterial gastrointestinal infections for both human and animals (Allocati et al. 2013). These bacteria are classified into a number of specific pathotypes such as enterotoxigenic, enteropathogenic, enteroinvasive, or enterohaemorrhagic according to the presence of specific virulence factors (Nataro and Kaper 1998). The differentiation between non-pathogenic commensal and pathogenic types of $E$. coli that may be present in the microflora of the intestinal tract of poultry at any one time remains a topic of considerable debate. For example, having 40 virulence determinants is sufficient for an E. coli isolate to be deseribed as an APEC type (Johnson et al. 2008), although it can be suggested that carriage of seven to nine virulence determinants may be a more accurate definition (Cordoni et al. 2016). Accurate differentiation is complex as it is not possible to perform infection studies in poultry for every isolate to confirm Koch's postulates. Moreover, pathogenic types residing in the gut before inducing disease, often occur as an opportunistic secondary infection to prior disease such as mycoplasmosis, which can confound results.

Traditionally, isolates belonging to $\mathrm{O} 1, \mathrm{O} 2$ and $\mathrm{O} 78$ serotypes are regarded as pathogenic (Ewers et al. 2003, Wang et al. 2014). Yet, this monothetic test is fallible because many other serotypes harbour APEC characteristics (Johnson et al. et al. 2008, Cordoni et al. et al. 2016). Several of the more commonly reported virulence factors associated with APEC include increased serum survival (iss), presence of type 1 fimbriae $($ fimH $), \mathrm{P}$ fimbriae (papC), and temperature-sensitive hemagglutinin $(t s h)$ of the autotransporter group of proteins (Delicato et al. et al. 2003, Ewers et al. 2004). These and many other virulence factors may be used to investigate isolates to differentiate between APEC strains associated with specific syndromes (Johnson et al. et al. 2008) but using these to differentiate commensals from 
APEC remains complicated. Whilst whole genome sequencing (Paixao et al. et al. 2016) is probably the most appropriate way to gain insights into these differences, it would be interesting to determine a set of relatively simple and readily transferable tests that front-line diagnostic laboratories, rather than specialist reference laboratories, can undertake. The aim of this preliminary study was to investigate the genotypic and phenotypic diversity of $E$. coli populations in poultry.

\section{Materials and Methods}

\section{E. coli strains}

Sixty-five defined and fully sequenced APEC isolated from E. coli infected, diseased chickens were provided by the University of Surrey (Cordoni et al. 2016), 35 isolates from caecal swabs from 35 healthy chickens and 100 isolates made from caecal swabs from 100 healthy turkeys reared at the University of Reading [CEDAR] farm, to give a total of 200 isolates. Chicken and turkey swab samples were grown on MacConkey agar and incubated at $37^{\circ} \mathrm{C}$ for $18-24 \mathrm{~h}$ aerobically. Well-isolated single pink colonies were picked and subcultured on selective media eosin methylene blue (EMB) to confirm the isolation of E. coli by lactose fermentation and acid production, shown as dark blue-black colonies with metallic green colonies. After isolation, E. coli were confirmed further using an indole test and API20E test kit according to manufacturer's protocol (BioMerieux, Lyon, France).

\section{Genomic DNA extraction and ERIC-PCR}

DNA was extracted from the 200 isolates using QIAGEN Puregene yeast/bacteria kit B and the manufacturer's standard protocol for fresh samples of Gram-negative bacteria were followed. DNA concentration was determined with a ND-1000 spectrophotometer, and DNA stocks at $100 \mathrm{ng} / \mu \mathrm{l}$ were prepared and stored at $-20^{\circ} \mathrm{C}$ until use. E. coli fingerprinting was 
performed using Enterobacterial repetitive intergenic consensus PCR (ERIC-PCR). The specific primers were ERIC1: 5'-ATGTAAGCTCCTGGGGATTCAC-3', and ERIC2: 5'AAGTAAGTGACTGGGGTGAGCG-3' (Ramazanzadeh et al. 2013). Each ERIC-PCR reaction was carried out in a total volume of $50 \mu 1$ Promega PCR mixture comprised of 100 ng of $E$. coli DNA, $1 \mu \mathrm{l}(25 \mathrm{pmol})$ of each primer, $1 \mu \mathrm{l}(200 \mathrm{mM})$ of dNTP mixture, $10 \mu \mathrm{l}$ of $5 \mathrm{X}$ buffer solution, $4 \mu \mathrm{l}(25 \mathrm{mM})$ of $\mathrm{MgCl}_{2}$, and $1 \mu \mathrm{l}(1.0 \mathrm{U})$ of $\mathrm{Taq}$ DNA polymerase (Promega Corporation, WI, USA). PCR amplification conditions were the same for all reactions and were carried out according to the following; initial denaturation at $94^{\circ} \mathrm{C}$ for 2 min, followed by 35 cycles of denaturation at $95^{\circ} \mathrm{C}$ for $30 \mathrm{~s}$, annealing at $52^{\circ} \mathrm{C}$ for $30 \mathrm{~s}$, extension at $72^{\circ} \mathrm{C}$ for $1 \mathrm{~min}$, and a final extension step at $72^{\circ} \mathrm{C}$ for $5 \mathrm{~min}$. Amplicons were examined by $1.5 \%$ TAE agarose gels electrophoresis. The data was analysed visually with DNA band sizes determined using the detect band button of NTSYSpc software Version 2.1b (Exeter Software, NY, USA).

\section{Virulence genotyping}

All E. coli samples were analysed for eleven APEC virulence factors using PCR assays. Virulence factor selection was based on the most virulent determinants associated with different diseases in poultry. Target genes and their descriptions are summarised in Table 1 with their respective primer sequences. All PCR assays were performed as above with $25 \mu 1$ of Promega PCR mixture and $1 \mu \mathrm{l}(25 \mathrm{pmol})$ of each primer. PCR amplification was according to the following; initial denaturation at $94^{\circ} \mathrm{C}$ for $3 \mathrm{~min}$, followed by 30 cycles of denaturation at $94^{\circ} \mathrm{C}$, for $30 \mathrm{~s}$, annealing at $58^{\circ} \mathrm{C}$ for $30 \mathrm{~s}$, extension at $68^{\circ} \mathrm{C}$ for $3 \mathrm{~min}$, and the final extension step at $72^{\circ} \mathrm{C}$ for $5 \mathrm{~min}$. Analysis of the amplified products was performed by $1.5 \%$ agarose gel electrophoresis.

Table 1 here 


\section{Carbon source utilisation test}

Two hundred strains of isolated E. coli were tested for their ability to utilise 11 substrates as sole sources of carbon and energy. Two to three colonies of each strain were inoculated on minimal salts medium (M9) prepared according to (Lee et al. 2010) with modification of the following carbon sources $(0.2 \% \mathrm{w} / \mathrm{v})$ : sucrose (suc), raffinose (raf), inositol (ino), adonitol (ado), arabitol (ara), dulcitol (dul), allantoin (all), proline (pro), sorbose (sor), melitzitose (mel), and salicin (sal). E. coli strains were streaked on to each plate and incubated at $37^{\circ} \mathrm{C}$ for $18-24$ hours, then incubated at $25^{\circ} \mathrm{C}$ for up to seven days. Results were recorded after 7 days' incubation.

\section{Antimicrobial susceptibility test}

Antimicrobial sensitivity was determined for the 200 isolated samples using the disc diffusion method (Bauer et al. 1966). Antimicrobial infused discs (Mast group, Mastdisks, UK) were used according to the standards and interpretation criteria described by National Committee for Clinical Laboratory Standards NCCLS/CLSI guidelines (Hsueh et al. 2010). The following antibiotics were used: nalidixic acid $(10 \mu \mathrm{g})$, amikacin $(30 \mu \mathrm{g})$, ampicillin $(10 \mu \mathrm{g})$, streptomycin $(10 \mu \mathrm{g})$, colistin sulphate $(10 \mu \mathrm{g})$, chloramphenicol $(30 \mu \mathrm{g})$, and trimethprim $(5 \mu \mathrm{g})$. E. coli were spread over the surface and plates were incubated at $37^{\circ} \mathrm{C}$ for $18-24$ hours and susceptibility was determined by measuring the zone of inhibition. The diameter of the zone of growth inhibition around each disc were measured and compared with zones of inhibition of standard controls according to standards of the NCCLS/CLSI (CLSI 2018).

\section{Data analysis}

ERIC fingerprint analyses were entered in the SAHN feature of the NTSYSpc software Version $2.1 \mathrm{~b}$ for the construction of dendrogram based on simple matching coefficient and 
UPGMA (Unweighted Pair Group Method for Arithmetic Averages) in cluster analysis to determine the genetic relatedness of the E. coli strains (Exeter Software, NY, USA). To determine the diversity between all characteristics tested by genotypic and phenotypic tests; a multivariate analysis of Principal Components Analysis (PCA) was used. The Pearson's correlation between all characteristics tested was determined by using Minitab version 17 software (Minitab, Inc., Coventry, UK). P-value of $<0.05$ was taken to indicates statistical significance.

\section{Results}

\section{Genotypic diversity}

The ERIC-PCR genotyping method results show the number of bands present, different sizes, and characteristic band patterns of E. coli strains' DNA fingerprints. One hundred and seventy-five fingerprinting patterns were determined among the 200 isolates. The sizes of the PCR products ranged from slightly less than $150 \mathrm{bp}$ to $>3000 \mathrm{bp}$ with products ranging from 450-1250 bp most commonly encountered. Out of the 200 isolates strains, 175 (87.5\%) were grouped in 31 groups that shared banding patterns indicative of a similar origin, and 25 (12.5\%) isolates displayed a single profile. A dendrogram based on simple matching coefficient (Figure 1) showed that at a coefficient of $0.089,31$ clusters and 25 singletons at a $\mathrm{D}$ value of 0.848 were identified. The index indicated that, if two strains were randomly sampled from the population, then, on $84.8 \%$ of occasions, they would fall into different types. Cluster 1 was the biggest cluster in the dendrogram having 76 E. coli strains and most of them were isolated from turkeys and only five from chickens. Similarly, E. coli strains in cluster 2 to cluster 10 were related to each other more than those in clusters 11 and 12 , as those strains were mixed turkey and chicken E. coli isolates. E. coli strains in clusters 16 to 22 were related to each other however, strains in clusters 17 to 22 were isolated from APEC 
strains. Twenty-five singleton (single isolates) E. coli strains were heterogenous and showed more distant relation to other $E$. coli strains at a coefficient of 0.089 , although, all singletons were isolated from chicken (12), and APEC (12) strains except for one isolated from turkey.

Figure 1 here

Two hundred $E$. coli strains were investigated for the presence of 11 virulence associated genes. The most frequently detected gene was $\mathrm{crl}$ that regulates the curli fimbrial operon, which was found in all strains (99.5\%) except for one turkey isolate. Figure 2 illustrates the detection frequency of each virulence factor assessed. Using the criterion that E. coli should have five or more virulence associated genes to be classified as APEC, these results show that 184 strains out of 200 strains could be classified as APEC strains according to that criterion (Table 2). However, if the criterion of seyen or more genes was used to classify APEC then 119 strains would be defined as APEC and less than half (37\%) of the turkey isolates would be defined as APEC. Whereas, $82.8 \%$ of chicken isolates would be classified as APEC, and 81.5\% of the chicken confirmed APEC isolates would be classified as APEC by the current assessment

Table 2 here

Figure 2 here 
To show the genetic divergence between $E$. coli strains generated by ERIC-PCR profiles and virulence associated genes, PCA analysis was performed. Score plots between the first two components for which the eigenvalues were most significant (6.1 and 2.6, respectively) showed the clear separation between turkey and APEC strains (Supplementary material S1). However, presumptive commensals from chickens were located between turkey and APEC strains.

\section{Phenotypic diversity}

A large subset of the 200 isolates were able to utilise the following carbon sources; dulcitol (galactitol) (38\%), sucrose $(37.5 \%)$, raffinose $(36 \%)$ and sorbose $(34.5 \%)$, irrespective of their source of isolation. Fewer strains, notably those isolated from APEC, could utilise proline $(7 \%)$, inositol (3\%), and salicin (1\%). No strains utilised either melezitose or allantoin. Most strains that could utilise raffinose were able to utilise sucrose. Strains isolated from Turkey utilised adonitol (ribitol) and arabitol, while other strains from chicken and APEC could not. (Figure 3).

Figure 3 here

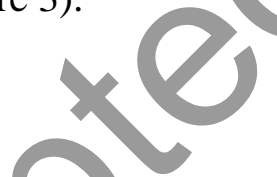

The 200 E. coli isolates were tested for antimicrobial susceptibility against seven antimicrobial agents using the disc diffusion method. The total number of isolates susceptible to all antibiotics tested was $87(43.5 \%)$. Susceptibility frequencies were $53 \%$ for turkey isolates, $34.2 \%$ chicken isolates and $33.8 \%$ for APEC isolates. APEC were resistant to most antimicrobials tested compared to either from turkey or chicken isolates but resistance to 
nalidixic acid and ampicillin was noted in a relatively high frequency (36\%-39\%) irrespective of the source of the isolates tested (Table 3).

Table 3

To estimate of the phenotypic diversity between E. coli isolates, a PCA was performed using carbon source utilisation and antimicrobial susceptibility variables. Score plots between the first 2 components for which the eigenvalues were 3.95 and 2.12 respectively, showed little separation between $E$. coli isolates, irrespective of origin (data not shown).

\section{Diversity Analysis using Combined Genotypic and Phenotypic Data}

To estimate diversity, the correlation between all genotypic and phenotypic characteristics in combination were evaluated. Figure 4 , represents the plot of the phenotypic distance $v s$. the genotypic distance between the isolated strains for which the eigenvalue for the first two components were highly significant (8.63 and 3.06; respectively). Turkey strains as well as 26 chicken isolates were clearly distant, both genetically and phenotypically, from APEC isolates and nine chicken isolates.

Figure 4

The relative diversity of $E$. coli isolates, as assessed by both genotypic and phenotypic tests, is shown graphically in Figure 5. Some variables were co-located into distinct two groups (A and B), and these groups are more likely to share specific traits indicating a high correlation 
between them. Group A showed clustering of many different antibiotic resistances, possibly because antibiotic resistance is often co-located on plasmids. Therefore, this clustering indicated acquisition of plasmids rather than any other trait. Whereas, group B were able to utilise proline, sucrose, raffinose, sorbose and dulcitol, and carried iucD, iss, cva/cvi and K1 virulence genes.

Figure 5

Significant correlations $(\mathrm{P}<0.05)$ between virulence genes and phenotypic characteristics in E. coli isolates were found for some variables (Supplementary S2). Arabitol and adontiol (ribitol) utilisation were negatively correlated with many virulence factors including $i u c D$, iss, $c v a / c v i$ and $\mathrm{k} 1$ capsule $(\mathrm{r}=-0.234,-0.308,-0.201$ and -0.231 ; respectively) and were inversely correlated with other carbon sources including; raffinose, dulcitol, proline, sorbose and sucrose. Conversely, utilisation of proline was associated with the same variables as arabitol and adonitol, but with a positive Pearson correlation with iucD, iss, cva/cvi and $k l$ (r $=0.258,0.195,0.26$ and 0.392 .

\section{Discussion}

Whilst there is increasing understanding of the diversity of APEC, the aim of this experiment was to determine whether relatively simple diagnostic laboratory tests could distinguish pathogenic strains from their commensal counterparts. The investigation used E. coli isolated from healthy chickens and turkeys from dietary investigation studies at CEDAR, the University of Reading farm, for comparison with confirmed APEC strains from previous work. 
The ERIC-PCR genotyping, in the main, grouped E. coli isolates by source and type confirming both the utility of this method and the findings of others (Maurer et al. 1998, Versalovic et al. 1991, Namvar and Warriner 2006).

Virulence factor genotyping of the 200 isolates revealed that a high percentage of them harbour virulence factors related to adhesion, iron acquisition and serum resistance, which are characteristic of the APEC pathotype (Delicato et al. et al. 2003). The most common virulence factors fimH, $c r l$, irp2 and $\operatorname{csg}$ were present in almost all the isolates, so these may not be associated with APEC specifically but may be considered ubiquitous systems for all $E$. coli. However, this does not preclude the fimbriae (type 1 and curli) from being considered potential virulence determinants, as they facilitate adherence which is important in the early stages of pathogenesis. The frequency of $t s h$, papC, ast $A$, iucD, and $k p s$ detection differed from previous reports (Dozois et al. et al. 2000, Zhao et al. et al. 2009, Guastalli 2013) and the iss gene was detected in the current isolates at a higher frequency than previously seen (Delicato et al. 2003, Rodriguez-Siek et al. 2005). These discrepancies might be explained by the limited selection of isolates used and the fact that the iss gene is carried on a plasmid associated with chicken species. Additionally, cva/cvi was present in $80 \%$ of APEC isolates suggesting that $c v a / c v i$ could be considered a potentially defining feature of the APEC strains (Vandekerchove et al.2005). Interestingly, if exclusion of three common virulence genes (crl, fim $\mathrm{H}$ and $c s g$ ), which were found in high percentages $(99.5 \%, 97 \%$ and $95.5 \%$; respectively), is considered, followed by applying the classification of E. coli into APEC if they harbour 5 or more virulence genes; the results changed to $13 \%$ APEC classified in turkey, $62.8 \%$ APEC from healthy chicken isolates, and $53.8 \%$ in the confirmed APEC isolates from chicken. Therefore, the question remains whether the selection of virulence genes for testing using the defined $\sim 40$ genes might be beyond a diagnostic laboratory, but remains a more relatively accurate method for APEC classification. Moreover, it is possible 
that other factors participate in the accurate classification of APEC strains, such as phenotypic characteristics.

The PCA plots suggested that presumptive commensal strains from chicken appear to share similarities with and sit between turkey presumptive commensals and APEC in terms of shared factors. The turkey isolates generally possessed far fewer virulence determinants whereas chicken isolates showed greater diversity, which probably represented genuine commensals. The data suggested that turkey isolates are more alike and may therefore be adapted to the turkey as a host. Given that $E$. coli related disease in turkey is relatively rare, the data suggested two possibilities. First, that these are genuine turkey related commensals lacking many virulence determinants or second, some are potential turkey pathogens but have yet undefined virulence determinants that are different from those associated with chickens.

The genotypic data suggested that the $E$. coli from healthy chickens were very diverse and many were potentially pathogenic. Interestingly, the results showed a higher than anticipated utilisation rate for L-sorbose, raffinose and dulcitol in APEC isolates. Interestingly, each of the three group of isolates could utilise, variably, only six substrates with the proportion of strains able to utilise a substrate dependent on the host from which they were isolated. This observation may indicate selection that was dependent upon what the animals were fed (Souza et al. 1999) and may be considered as possible discriminatory substrates for screening and identification of pathogenicity (Ratnam et al. 1988, Durso et al. 2004).

Only presumptive commensal strains isolated from turkeys utilised adonitol (ribitol) and arabitol, although these two sugars (pentitols) are relatively abundant in nature. Woodward and Charles (1983) demonstrated that the genes for dulcitol (galactitol) utilisation and those for adonitol and arabitol utilisation are mutually exclusive at minute 44 on the $E$. coli genome (Woodward and Charles 1983). It seems likely that testing for growth on these pentitols may 
provide the easiest way to distinguish commensal E. coli strains of turkeys from chicken strains if this correlation can be confirmed by further studies that make use of a much wider collection of $E$. coli sources. The ability to utilise proline as a sole energy source was limited to APEC strains, although only $21.5 \%$ were positive for this characteristic. Whether this will be a useful differential marker requires further testing.

Antimicrobial treatment is the most commonly used control measures for reducing morbidity and mortality caused by APEC in poultry (Dho-Moulin and Fairbrother 1999, Guerra et al. 2003) but has the consequence of high incidence of resistance. Whilst many isolates were susceptible to most of the antimicrobials tested, confirmed APEC isolates showed the highest resistance, confirming the findings of other reports (Kazemnia et al. 2014, Salehi and Bonab 2006, Mellata 2013).

There was a significant negative correlation between utilisation of the carbon sources arabitol and adonitol with the different virulence determinants tested, such as, iucD, iss, $c v a / c v i$ and k1. Moreover, utilisation of proline was associated with the same genetic variables as arabitol and adonitol but with a positive correlation with iucD, iss, $c v a / c v i$ and $k l$. Thus, a strong correlation between the virulence genes and phenotypic characteristics suggested that the ability to utilise some uncommon carbon sources may discriminate between presumptive commensal E. coli and APEC. Whilst it is recognised that these hypotheses require a wider study using isolates made from many different geographic locations and management systems, if confirmed, simple tests may enable differentiation of APEC from harmless commensals. Based on these findings, the next step is confirmation of Koch's postulates in appropriate in vivo models. 
Acknowledgements: We acknowledge the gift of strains from the Veterinary School and of the University of Surrey (Roberto La Ragione) and colleagues at CEDAR and the Department of Agriculture (Caroline Rymer and Darren Junper) for access to chicken and poultry studies for the isolation of E. coli.

Conflict of interest: none

Funding source: Kuwait Government- public authority of agriculture and fish resources

\section{References}

Allocati, N., M. Masulli, M. F. Alexeyev, and C. Di Hio, 2013. "Escherichia coli in Europe: an overview." International journal of environmental research and public health no. 10 (12):6235-54. doi: 10.3390/ijerph10126235.

Bauer, A. W., W. M. Kirby, J. C. Sherris, and M. Turck. 1966. "Antibiotic susceptibility testing by a standardized single disk method." American journal of clinical pathology no. 45 (4):493-6.

CLSI. 2018. Performance Standards for Antimicrobial Susceptibility Testing. 28 ed, CLSI supplement M100. Wayne, PA: Clinical and Laboratory Standards Institute.

Cordoni, G., M. J. Woodward, H. Wu, M. Alanazi, T. Wallis, and R. M. La Ragione. 2016. "Comparative genomics of European avian pathogenic E. coli (APEC)." BMC genomics no. 17,(1):960. doi: 10.1186/s12864-016-3289-7.

Delicato, E. R., B. G. de Brito, L. C. Gaziri, and M. C. Vidotto. 2003. "Virulence-associated genes in Escherichia coli isolates from poultry with colibacillosis." Veterinary microbiology no. 94 (2):97-103.

Dho-Moulin, M., and J. M. Fairbrother. 1999. "Avian pathogenic Escherichia coli (APEC)." no. $30(2-3): 299-316$.

Dozois, C. M., M. Dho-Moulin, A. Bree, J. M. Fairbrother, C. Desautels, and R. Curtiss, 3rd. 2000. "Relationship between the Tsh autotransporter and pathogenicity of avian Escherichia coli and localization and analysis of the Tsh genetic region." Infection and immunity no. 68 (7):4145-54.

Durso, L. M., D. Smith, and R. W. Hutkins. 2004. "Measurements of fitness and competition in commensal Escherichia coli and E. coli O157:H7 strains." Applied and environmental microbiology no. 70 (11):6466-72. doi: 10.1128/aem.70.11.64666472.2004 .

Ewers, C., T. Janssen, S. Kiessling, H. C. Philipp, and L. H. Wieler. 2004. "Molecular epidemiology of avian pathogenic Escherichia coli (APEC) isolated from colisepticemia in poultry." no. 104 (1-2):91-101. doi: S0378-1135(04)00331-1 [pii]

10.1016/j.vetmic.2004.09.008. 
Ewers, C., T. Janssen, S. Kiessling, H. C. Philipp, and L. H. Wieler. 2005. "Rapid detection of virulence-associated genes in avian pathogenic Escherichia coli by multiplex polymerase chain reaction." Avian diseases no. 49 (2):269-73.

Ewers, C., T. Janssen, and L. H. Wieler. 2003. "[Avian pathogenic Escherichia coli (APEC)]." no. 116 (9-10):381-95.

Ewers, C., G. Li, H. Wilking, S. Kiessling, K. Alt, E. M. Antao, C. Laturnus, I. Diehl, S. Glodde, T. Homeier, U. Bohnke, H. Steinruck, H. C. Philipp, and L. H. Wieler. 2007. "Avian pathogenic, uropathogenic, and newborn meningitis-causing Escherichia coli : how closely related are they?" International journal of medical microbiology : IJMM no. 297 (3):163-76. doi: 10.1016/j.ijmm.2007.01.003.

Franck, S. M., B. T. Bosworth, and H. W. Moon. 1998. "Multiplex PCR for enterotoxigenic, attaching and effacing, and Shiga toxin-producing Escherichia coli strains from calves." Journal of clinical microbiology no. 36 (6):1795-7.

Guastalli, E., Guastalli, B., Soares, N., Leite, D., Ikuno, A., Maluta,R., Cardozo, M., Beraldo, L., Borges, C. and Ávila, F. 2013. "Virulence characteristics of Escherichia coli isolates obtained from commercial one-week-old layer chicks with diarrhea." no. 7 (47):5306-5313. doi: 10.5897/AJMR20.

Guerra, B., E. Junker, A. Schroeter, B. Malorny, S. Lehmann, and R. Helmuth. 2003. "Phenotypic and genotypic characterization of antimicrobial resistance in German Escherichia coli isolates from cattle, swine and poultry." The Journal of antimicrobial chemotherapy no. 52 (3):489-92. døi: 10.1093/jac/dkg362.

Hsueh, P. R., W. C. Ko, J. J. Wu, J. J. Lu, F. D. Wang, H. Y. Wu, T. L. Wu, and L. J. Teng. 2010. "Consensus statement on the adherence to Clinical and Laboratory Standards Institute (CLSI) Antimicrobial Susceptibility Testing Guidelines (CLSI-2010 and CLSI-2010-update) for Enterobacteriaceae in clinical microbiology laboratories in Taiwan." Journal of microbiology, immunology, and infection $=$ Wei mian yu gan ran za zhi no. 43 (5):452-5. doi: 10.1016/s1684-1182(10)60070-9.

Janben, T., C. Schwarz, P. Preikschat, M. Voss, H. C. Philipp, and L. H. Wieler. 2001. "Virulence-associated genes in avian pathogenic Escherichia coli (APEC) isolated from internal organs of poultry having died from colibacillosis." International journal of medical microbiology: IJMM no. 291 (5):371-8.

Johnson, T. J., Y. Wannemuehler, C. Doetkott, S. J. Johnson, S. C. Rosenberger, and L. K. Nolan. 2008. "Identification of minimal predictors of avian pathogenic Escherichia coli virulence for use as a rapid diagnostic tool." no. 46 (12):3987-96. doi: JCM.00816-08 [pii]

10.1128/JCM.00816-08.

Kazemnia, A., M. Ahmadi, and M. Dilmaghani. 2014. "Antibiotic resistance pattern of different Escherichia coli phylogenetic groups isolated from human urinary tract infection and avian colibacillosis." Iranian biomedical journal no. 18 (4):219-24.

Knobl, T., A. M. Moreno, R. Paixao, T. A. Gomes, M. A. Vieira, D. da Silva Leite, J. E. Blanco, and A. J. Ferreira. 2012. "Prevalence of avian pathogenic Escherichia coli (APEC) clone harboring sfa gene in Brazil." no. 2012:437342. doi: 10.1100/2012/437342.

Lee, J. W., S. Choi, J. H. Park, C. E. Vickers, L. K. Nielsen, and S. Y. Lee. 2010. "Development of sucrose-utilizing Escherichia coli K-12 strain by cloning betafructofuranosidases and its application for L-threonine production." Applied microbiology and biotechnology no. 88 (4):905-13. doi: 10.1007/s00253-010-2825-7. 
Maurer, J. J., M. D. Lee, C. Lobsinger, T. Brown, M. Maier, and S. G. Thayer. 1998. "Molecular typing of avian Escherichia coli isolates by random amplification of polymorphic DNA." Avian diseases no. 42 (3):431-51.

Mellata, M. 2013. "Human and avian extraintestinal pathogenic Escherichia coli : infections, zoonotic risks, and antibiotic resistance trends." Foodborne pathogens and disease no. 10 (11):916-32. doi: 10.1089/fpd.2013.1533.

Namvar, A., and K. Warriner. 2006. "Application of enterobacterial repetitive intergenic consensus-polymerase chain reaction to trace the fate of generic Escherichia coli within a high capacity pork slaughter line." International journal of food microbiology no. 108 (2):155-63. doi: 10.1016/j.ijfoodmicro.2005.11.006.

Nataro, J. P., and J. B. Kaper. 1998. "Diarrheagenic Escherichia coli ." Clinical microbiology reviews no. 11 (1):142-201.

Paixao, A. C., A. C. Ferreira, M. Fontes, P. Themudo, T. Albuquerque, M. C. Soares, M. Fevereiro, L. Martins, and M. I. Correa de Sa. 2016. "Detection of virulenceassociated genes in pathogenic and commensal avian Escherichia coli isolates." Poultry science no. 95 (7):1646-52. doi: 10.3382/ps/pew087.

Ramazanzadeh, R., S. Zamani, and S. Zamani. 2013. "Genetic diversity in clinical isolates of Escherichia coli by enterobacterial repetitive intergenic consensus (ERIC)-PCR technique in Sanandaj hospitals." Iranian journal of microbiology no. 5 (2):126-31.

Ratnam, S., S. B. March, R. Ahmed, G. S. Bezanson, and S. Kasatiya. 1988. "Characterization of Escherichia coli serotype O157:H7." Journal of clinical microbiology no. 26 (10):2006-12.

Rodriguez-Siek, K. E., C. W. Giddings, C. Doetkott, T. J. Johnson, and L. K. Nolan. 2005. "Characterizing the APEC pathotype." Veterinary research no. 36 (2):241-56. doi: 10.1051/vetres:2004057.

Salehi, T.Z., and S.F. Bonab. 2006. "Antibiotics Susceptibility Pattern of Escherichia coli Strains Isolated from Chickens with Colisepticemia in Tabriz Province, Iran " no. 5 ( 7): 677-684.

Schubert, S., A. Rakin, H. Karch, E. Carniel, and J. Heesemann. 1998. "Prevalence of the "high-pathogenicity island" of Yersinia species among Escherichia coli strains that are pathogenic to humans." Infection and immunity no. 66 (2):480-5.

Souza, V., M. Rocha, A. Valera, and L. E. Eguiarte. 1999. "Genetic structure of natural populations of Escherichia coli in wild hosts on different continents." Applied and environmental microbiology no. 65 (8):3373-85.

Vandekerchove, D., F. Vandemaele, C. Adriaensen, M. Zaleska, J. P. Hernalsteens, L. De Baets, P. Butaye, F. Van Immerseel, P. Wattiau, H. Laevens, J. Mast, B. Goddeeris, and F. Pasmans. 2005. "Virulence-associated traits in avian Escherichia coli: comparison between isolates from colibacillosis-affected and clinically healthy layer flocks." Veterinary microbiology no. 108 (1-2):75-87. doi: 10.1016/j.vetmic.2005.02.009.

Versalovic, J., T. Koeuth, and J. R. Lupski. 1991. "Distribution of repetitive DNA sequences in eubacteria and application to fingerprinting of bacterial genomes." Nucleic acids research no. 19 (24):6823-31.

Wang, S., Q. Meng, J. Dai, X. Han, Y. Han, C. Ding, H. Liu, and S. Yu. 2014. "Development of an allele-specific PCR assay for simultaneous sero-typing of avian pathogenic Escherichia coli predominant O1, O2, O18 and O78 strains." no. 9 (5):e96904. doi: 10.1371/journal.pone.0096904

PONE-D-13-46496 [pii]. 
Woodward, M. J., and H. P. Charles. 1983. "Polymorphism in Escherichia coli : rtl atl and gat regions behave as chromosomal alternatives." Journal of general microbiology no. 129 (1):75-84. doi: 10.1099/00221287-129-1-75.

Zhao, L., S. Gao, H. Huan, X. Xu, X. Zhu, W. Yang, Q. Gao, and X. Liu. 2009. "Comparison of virulence factors and expression of specific genes between uropathogenic Escherichia coli and avian pathogenic E. coli in a murine urinary tract infection model and a chicken challenge model." Microbiology (Reading, England) no. 155 (Pt 5):1634-44. doi: 10.1099/mic.0.024869-0. 
Table 1: The primers used for detection of the various genes by PCR, amplicon size, encoded virulence factors and primer references were used.

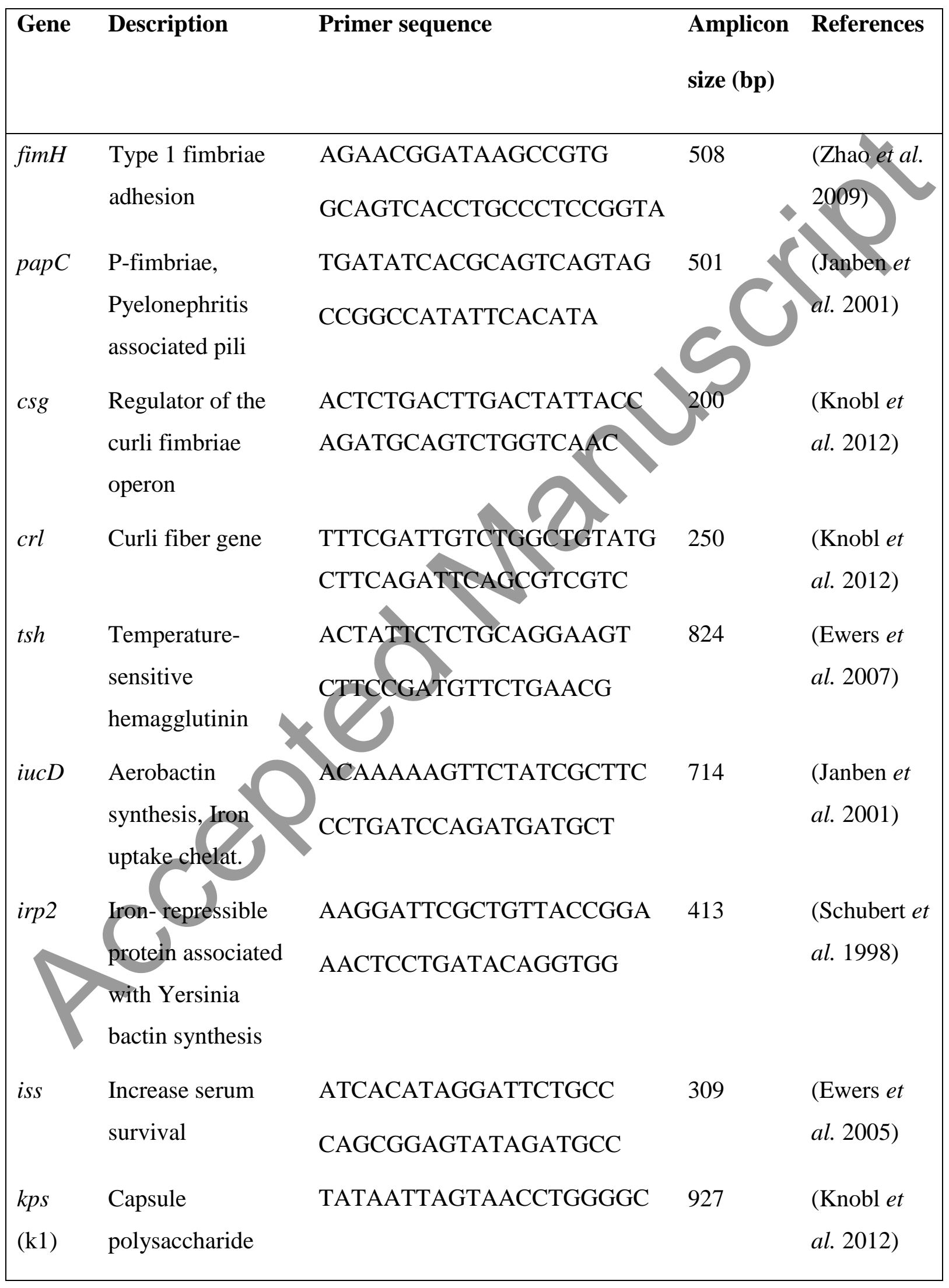




\begin{tabular}{|c|c|c|c|c|}
\hline & & GGCGCTATTGAATAAGACTG & & \\
\hline astA & Enteroaggregative & TGCCATCAACACAGTATATC & 116 & (Franck et \\
\hline & heat-stable toxin & TCAGGTCGCGAGTGACGG & & al. 1998) \\
\hline$c v a / c v i$ & Structural genes of & TCCAAGCGGACCCCTTATAG & 598 & (Ewers et \\
\hline & colicin V operon & CGCAGCATAGTTCCATGCT & & al. 2007) \\
\hline
\end{tabular}

Table 2. Prevalence of virulence-associated genes in APEC field strains, as detected by PCR.

\begin{tabular}{|c|c|c|c|c|c|c|c|c|c|c|c|}
\hline Samples(n) & crl & $\begin{array}{r}\text { fim } \\
\boldsymbol{H}\end{array}$ & $\operatorname{csg}$ & $\begin{array}{c}\text { irp } \\
2\end{array}$ & iss & iuc & 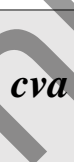 & tsh & $\begin{array}{c}\text { ast } \\
\text { A }\end{array}$ & K1 & $\begin{array}{r}\text { pap } \\
C\end{array}$ \\
\hline Turkey (100) & 99 & 97 & 96 & 92 & & 31 & 30 & 39 & 44 & 4 & 3 \\
\hline$\%$ & 99 & 97 & & 92 & & 31 & 30 & 39 & 44 & 4 & 3 \\
\hline Chicken (35) & 35 & 34 & & 30 & 32 & 32 & 19 & 20 & 27 & 7 & 1 \\
\hline$\%$ & 100 & & 100 & $\begin{array}{c}85 . \\
7\end{array}$ & $\begin{array}{c}91 . \\
4\end{array}$ & 91.4 & $\begin{array}{r}54 . \\
2\end{array}$ & $\begin{array}{c}57 . \\
1\end{array}$ & 77.1 & 20 & 2.8 \\
\hline APEC (65) & & & 60 & 55 & 61 & 60 & 52 & 38 & 11 & 20 & 5 \\
\hline & 100 & 96.9 & $\begin{array}{c}92 . \\
3\end{array}$ & $\begin{array}{c}84 . \\
6\end{array}$ & $\begin{array}{c}93 . \\
8\end{array}$ & 92.3 & 80 & $\begin{array}{r}58 . \\
4\end{array}$ & 16.9 & $\begin{array}{c}30 . \\
7\end{array}$ & 7.6 \\
\hline Total (200) & 199 & 194 & 191 & 177 & 148 & 123 & 101 & 97 & 82 & 31 & 9 \\
\hline$\%$ & 99.5 & 97 & $\begin{array}{c}95 . \\
5\end{array}$ & $\begin{array}{c}88 . \\
5\end{array}$ & 74 & 61.5 & $\begin{array}{r}50 . \\
5\end{array}$ & $\begin{array}{r}48 . \\
5\end{array}$ & 41 & $\begin{array}{c}15 . \\
5\end{array}$ & 4.5 \\
\hline
\end{tabular}


Table 3. Percentages of $E$. coli isolates, susceptible, intermediate and resistant to antimicrobial agents.

\begin{tabular}{|c|c|c|c|}
\hline \multirow{2}{*}{ Antimicrobial agent $(\mu \mathrm{g})$} & \multicolumn{3}{|c|}{$n=200$} \\
\hline & Susceptible & Intermediate & Resistant \\
\hline Nalidixic acid (10 $\mu g)$ & $122(61 \%)$ & $6(3 \%)$ & $72(36 \%)$ \\
\hline Amikacin $(30 \mu g)$ & $184(92 \%)$ & $4(2 \%)$ & $13(6.5 \%)$ \\
\hline Ampicillin $(10 \mu g)$ & $114(57 \%)$ & $7(3.5 \%)$ & $79(39.5 \%)$ \\
\hline Chloramphenicol $(30 \mu \mathrm{g})$ & $184(92 \%)$ & $8(4 \%)$ & $8(4 \%)$ \\
\hline Colistin $(10 \mu \mathrm{g})$ & $190(95 \%)$ & $4(2 \%)$ & \\
\hline Streptomycin $(10 \mu g)$ & $165(82.5 \%)$ & $20(10 \%)$ & \\
\hline Trimethoprim $(5 \mu \mathrm{g})$ & $174(87 \%)$ & & \\
\hline
\end{tabular}




\section{Figure Captions}

Figure 1. Dendrogram of genomic similarity of 200 E. coli strains using ERIC-PCR result.

C1-C31=E. coli clusters 1-31, S1-S25=E. coli singletons 1-25, T=turkey (green),

$\mathrm{Ch}=$ chicken (orange) and $\mathrm{A}=\mathrm{APEC}$ (blue).

Figure 2. Total detection rates of virulence-associated genes in isolates.

Figure 3. Percentage of carbon sources utilised in isolated $E$. coli strains from different sources grown on minimal medium with eleven different carbon source substrates.

Figure 4. Relationship between the phenotypic distance, and the genetic distance, resulting from comparisons between $200 E$. coli strains, T=turkey (green), C=chicken (red) and A=APEC (blue). First component was genotypic characteristics and second component was phenotypic characteristics.

Figure 5. Correlation between the virulence genes, carbon sources utilised and antimicrobials agent between 200 E. coli strains. First component was genotypic characteristics and second component was phenotypic characteristics 


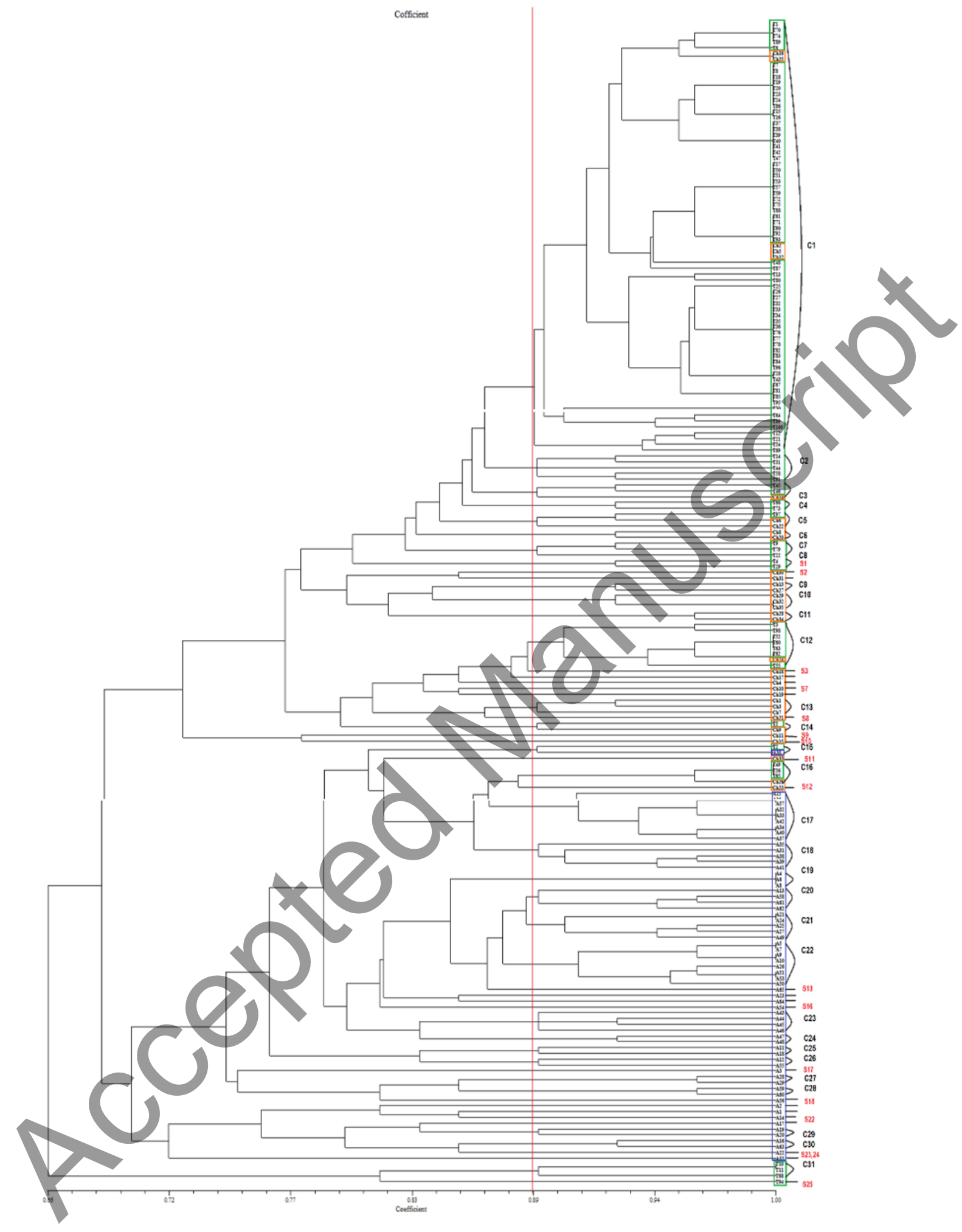

Figure 1 


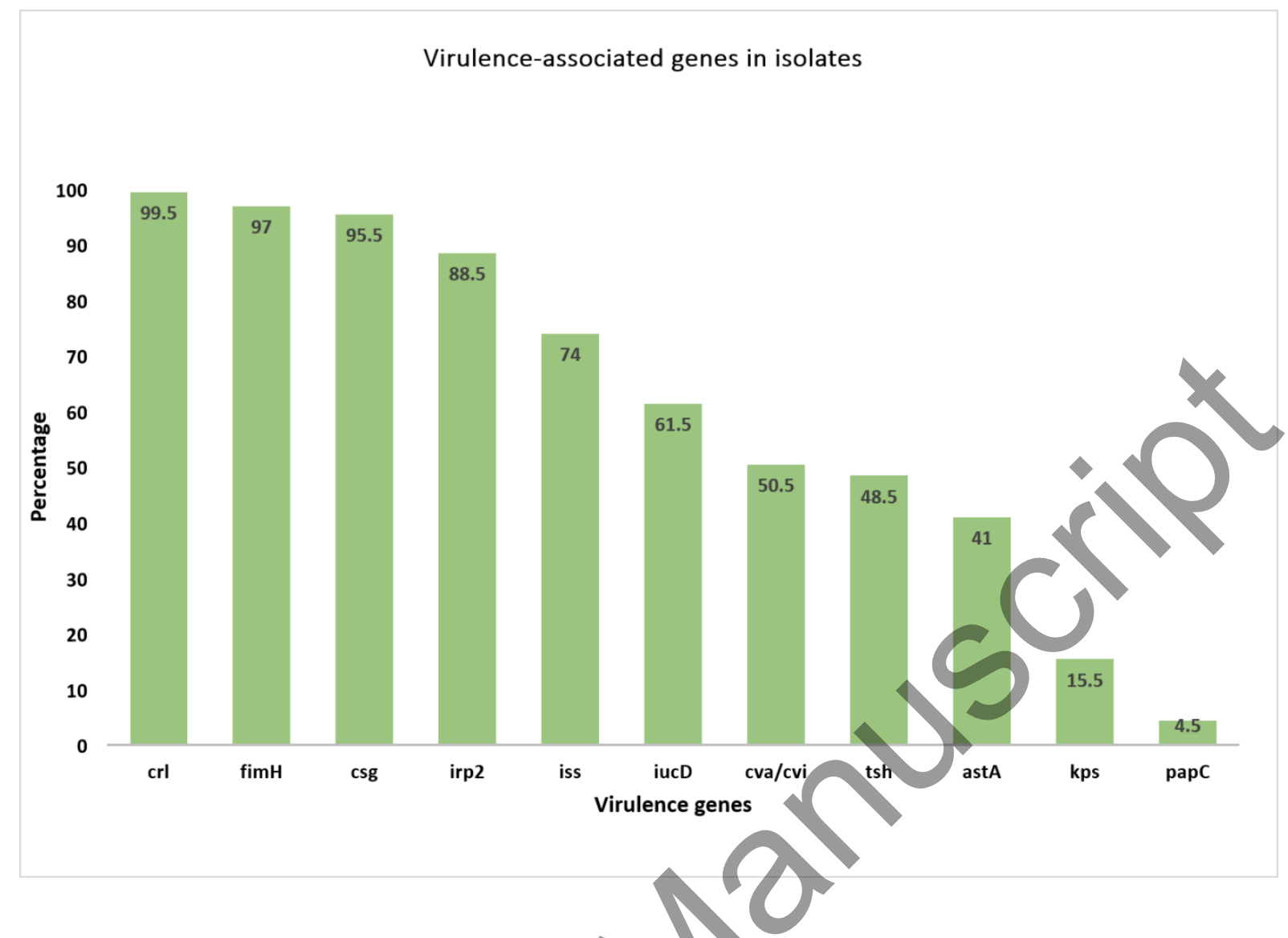

Figure 2

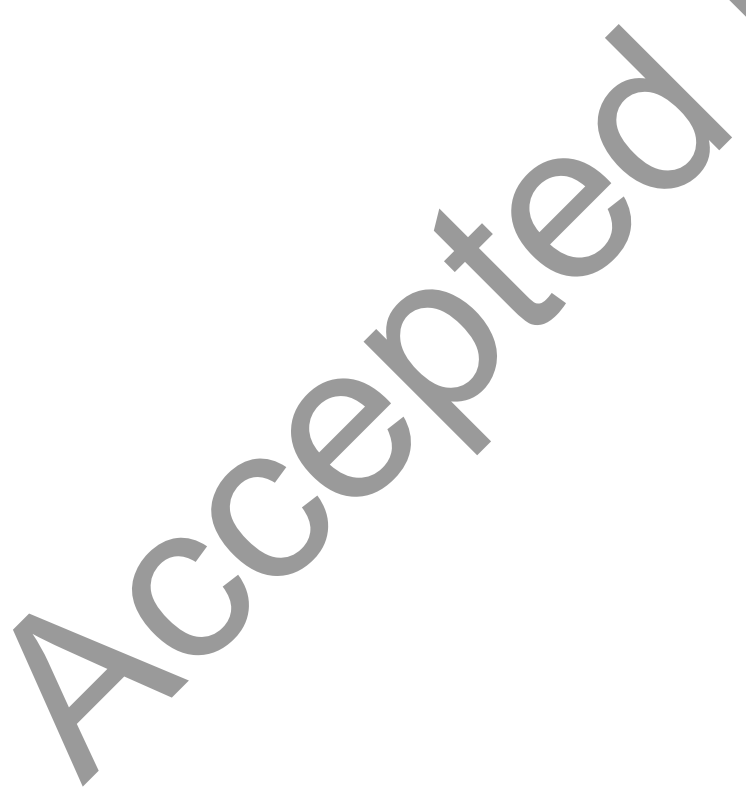


Percentage Of Carbon Substrates Utilisation

40

w Turkey $\quad$ Chicken $\square$ APEC

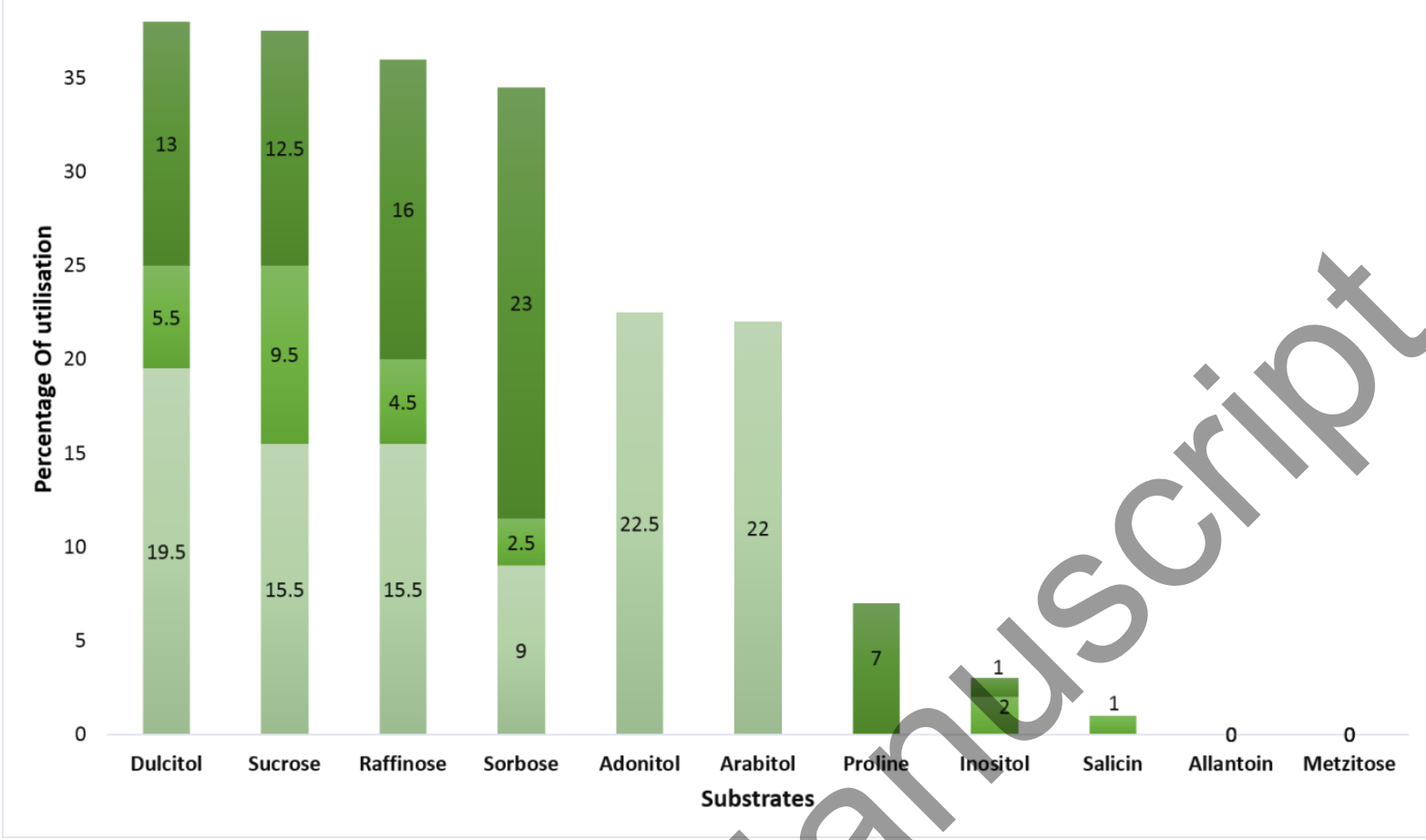

Figure 3 
Score Plot of all characteristics of genotypic and phenotypic diversity

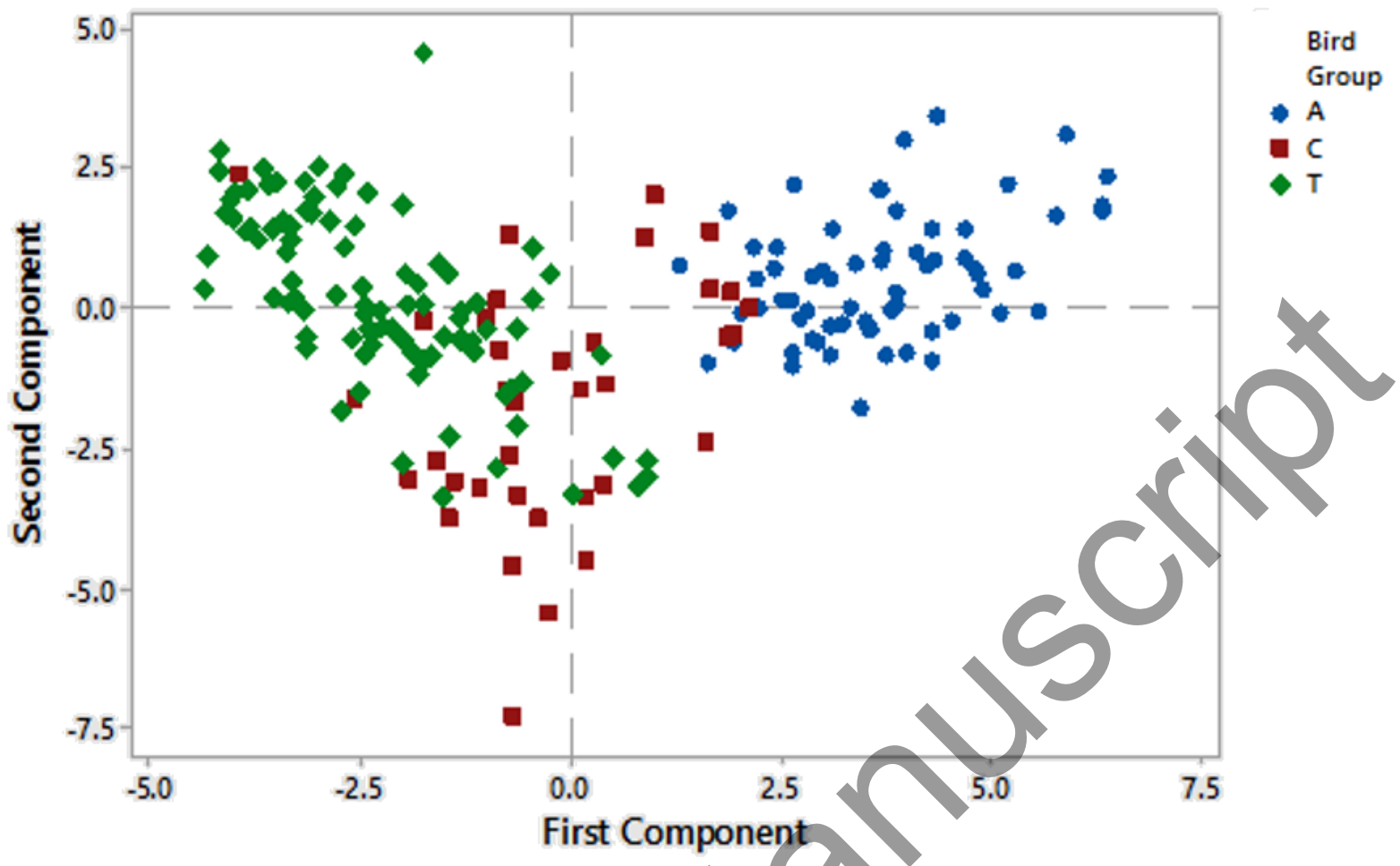

Figure 4 
Plot of virulence genes, carbon sources and antimicrobials

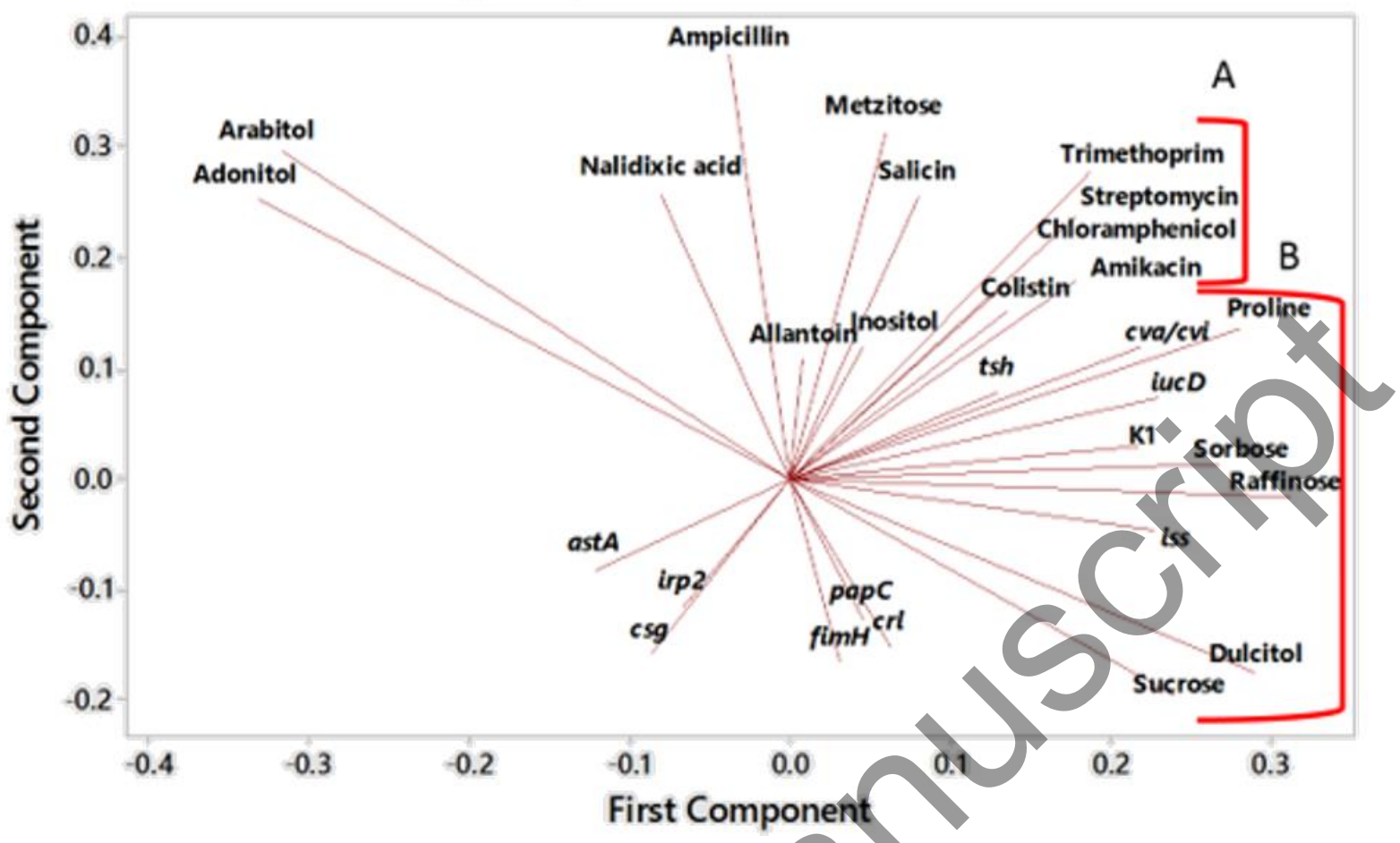

Figure 5 